\title{
Effect of Mono- and Di-hydration on the Intramolecular Proton Transfers and Stability of Cyanuric Acid Isomers: A DFT Study
}

\author{
YOUNES VALADBEIGI \\ Department of Chemistry, Science and Research Branch, Islamic Azad University, Tehran, Iran \\ e-mail: y.valadbeigi@ch.iut.ac.ir
}

MS received 15 May 2016; revised 28 June 2016; accepted 28 June 2016

\begin{abstract}
Structural and thermodynamic properties of 10 isomers of cyanuric acid were studied in aqueous and gas phases, employing B3LYP/6-311++G(d,p) method. The aromaticities of these isomers were evaluated using nucleus-independent chemical shift (NICS) index. The calculations showed that as the number of the keto groups increases the stability of the isomers increases and the aromaticity decreases. Mono- and di-hydrations of the isomers did not change the stability trend, so that the tri-keto isomer was the most stable isomer among the hydrated and non-hydrated isomers. The activation energies $\left(E_{a}\right)$ of the intramolecular proton transfers (tautomerisms) and energy barriers of $\mathrm{H}$-rotations around its $\mathrm{C}-\mathrm{O}$ axis in enolic isomers were calculated. The energy barriers were smaller than $45 \mathrm{~kJ} / \mathrm{mol}$ for the H-rotations while the $\mathrm{E}_{\mathrm{a}}$ values of the proton transfers were in the range of 130-210 kJ/mol. Effect of micro-hydrations on the transition state structures and the energy barriers of the tautomerisms were investigated. The mono- and di-hydrations lower the activation energies to $100-130 \mathrm{~kJ} / \mathrm{mol}$ and $110-145 \mathrm{~kJ} / \mathrm{mol}$, respectively.
\end{abstract}

Keywords. Cyanuric acid; micro-hydration; aromaticity; proton transfer; energy barrier.

\section{Introduction}

Cyanuric acid $\left(\mathrm{C}_{3} \mathrm{H}_{3} \mathrm{~N}_{3} \mathrm{O}_{3}\right)$ is a triazine molecule which can exist in keto and enol forms. ${ }^{1-3}$ Due to its structure, cyanuric acid can act as hydrogen bond donor and acceptor at the same time, ${ }^{4-7}$ and therefore, it has been used in the formation of self-assembled nanostructures through hydrogen bond networks. ${ }^{8}{ }^{8}$ Experimental and theoretical studies have reported that the tri-keto isomer is the most stable structure of cyanuric acid in all phases. ${ }^{1,2,10,11}$ The theoretical studies show that the triketo isomer is more stable than the tri-enol isomer by about $117^{1}$ and $129^{2} \mathrm{~kJ} / \mathrm{mol}$ in gas phase and aqueous solution, respectively. However, Prabhaharan et al., ${ }^{12}$ studied the cyanuric acid structure using FT-IR and FT-Raman spectroscopy and attributed the observed vibrations to the tri-enol isomer of cyanuric acid.

Keto-enol tautomerism is intramolecular proton transfer which has been well-studied for many important molecules. ${ }^{13-15}$ Kroke et al., ${ }^{16}$ and Liang et al., ${ }^{1}$ studied keto-enol tautomerisms in cyanuric acid. Liang et al., ${ }^{1}$ calculated the energy barriers for the interconversion of the tri-keto isomer to the tri-enol isomer through sequential proton transfer. They reported the structural properties of three transition state structures and four tautomers of cyanuric acid. Zabardasti et al. ${ }^{3}$ have studied mono-, di- and tri-hydrations of only the tri-keto isomers of cyanuric acid and reported the structural parameters of the formed clusters.
The tri-keto and tri-enol isomers of cyanuric acid have been well studied while it can have more isomers. In this work, we study the structural and thermodynamic properties of 10 isomers of cyanuric acid using DFT methods. Effects of mono- and di-hydration on the relative stability of the isomers and energy barriers of their tautomerisms are investigated.

\section{Computational Details}

The structures of the cyanuric isomers, their hydrated forms and the transition state (TS) structures were fully optimized at the B3LYP level of theory using 6-311 $++\mathrm{G}(\mathrm{d}, \mathrm{p})$ basis set. Frequency calculations were also performed at the same level on all the structures in order to obtain their thermodynamic quantities. The TS structures were optimized using OPT $=\mathrm{TS}$ keyword, then, the correctness of the obtained TS structures was confirmed employing intrinsic reaction coordinate (IRC) ${ }^{17}$ calculations. The activation energies of the proton transfers and O-H rotations were obtained from the energy differences between the TS structures and the corresponding stable isomers. Tomasi's polarized continuum model $(\mathrm{PCM})^{18}$ was used for the calculations in aqueous phase. The nucleus-independent chemical shift (NICS) index ${ }^{19,20}$ was calculated at the center of the molecule ring, NICS(0), and $1 \AA$ above the ring, NICS(1), using 
gauge-independent atomic orbital (GIAO) method and the $\mathrm{Bq}$ atom as a probe. The negative values of isotropic NICS at the ring center, NICS $(0)_{\text {ISO }}$, and the out-of-plane component of the NICS(1) index, NICS(1) $)_{\mathrm{ZZ}}$, were reported as the aromaticity indices. All calculations were performed using the Gaussian 09 software. ${ }^{21}$

\section{Results and Discussion}

Figure 1 shows 10 isomers of cyanuric acid optimized at the B3LYP/6-311++G(d,p) level of theory. The geometric parameters of the cyanuric acid isomers are given in Supplementary Information (Figure S1). The isomers I and II have three enol groups without any keto group and other isomers have 1, 2 or 3 keto groups. The isotropic NICS indices at the center of the cyanuric acid rings, NICS $(0)_{\text {ISO }}$, and out-of-plane component of the NICS index $1 \AA$ above the rings, NICS $(1)_{\mathrm{ZZ}}$, have been tabulated in Table 1 . Both NICS(0) ISO $_{\text {and }}$ NICS $(1)_{\text {ZZ }}$ values are more negative for the isomer I and II, indicating they are more aromatic than other isomers. Furthermore, as the number of keto groups increases, the aromaticity of the cyanuric acid isomers decreases. Fallah-BagherShaidaei et al. ${ }^{20}$ evaluated five NICS indices for 75 aromatic molecules and found that the NICS $(1)_{\mathrm{ZZ}}$ is a better index than the NICS $(0)_{\text {ISO }}$ for prediction of aromaticity. Table 1 shows that the NICS $(1)_{\text {zz }}$ index shows the change in the aromaticity as a function of the number of the keto groups. The NICS values show that the isomer $\mathrm{X}$ with three keto groups is an antiaromatic molecule.

To compare the stability of the cyanuric isomers, their enthalpies $(\Delta H)$ and Gibbs free energies $(\Delta G)$ were calculated in aqueous and gas phases. Table 1 summarizes the relative $\Delta \mathrm{H}$ and $\Delta \mathrm{G}$ values of the isomers as well as their zero point energies (ZPE). The difference in the $\mathrm{ZPE}$ values is about $1-5 \mathrm{~kJ} / \mathrm{mol}$; therefore, the ZPEcorrected and uncorrected energies have the same stability trends. Based on the aromaticity and the NICS values, it is expected that the isomer I and II to be more stable than other isomers, however, the thermodynamic
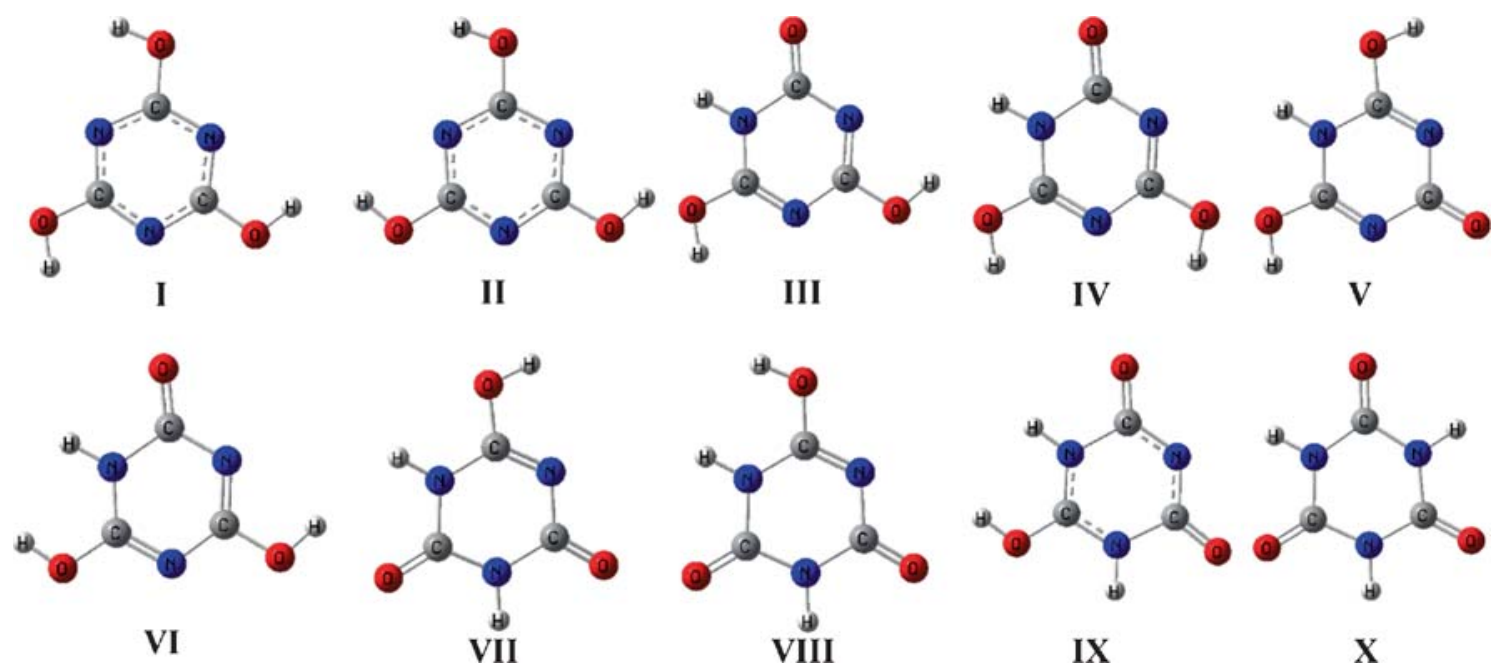

Figure 1. The optimized structures of the 10 isomers of cyanuric acid.

Table 1. The enthalpies $(\Delta \mathrm{H})$ and Gibbs free energies $(\Delta \mathrm{G})$ of the cyanuric acid isomers relative to the isomer $\mathrm{X}$ and their zero point energies $(\mathrm{ZPE})$. NICS $(0)_{\mathrm{ISO}}$ and NICS $(1)_{\mathrm{ZZ}}$ are in $\mathrm{ppm}$.

\begin{tabular}{|c|c|c|c|c|c|c|c|c|}
\hline \multirow[b]{2}{*}{ Isomer } & \multicolumn{5}{|c|}{ Gas Phase } & \multicolumn{3}{|c|}{ Aqueous } \\
\hline & $\operatorname{NICS}(0)_{\text {ISO }}$ & $\operatorname{NICS}(1)_{\mathrm{ZZ}}$ & $\Delta \mathrm{H}(\mathrm{kJ} / \mathrm{mol})$ & $\Delta \mathrm{G}(\mathrm{kJ} / \mathrm{mol})$ & ZPE (kJ/mol) & $\Delta \mathrm{H}(\mathrm{kJ} / \mathrm{mol})$ & $\Delta \mathrm{G}(\mathrm{kJ} / \mathrm{mol})$ & $\mathrm{ZPE}(\mathrm{kJ} / \mathrm{mol})$ \\
\hline I & -5.37 & -14.15 & 122.56 & 125.81 & 210.88 & 131.24 & 133.34 & 208.7456 \\
\hline II & -5.30 & -14.15 & 126.84 & 129.96 & 210.67 & 131.75 & 133.89 & 208.8165 \\
\hline III & -2.72 & -5.41 & 115.96 & 117.87 & 209.55 & 110.48 & 111.82 & 208.3413 \\
\hline IV & -2.81 & -5.27 & 125.77 & 127.27 & 208.84 & 112.76 & 114.01 & 208.3203 \\
\hline V & -2.20 & -4.32 & 157.17 & 157.12 & 207.50 & 137.76 & 138.22 & 207.4303 \\
\hline VI & -3.02 & -5.65 & 148.27 & 148.69 & 207.36 & 125.22 & 125.64 & 207.5537 \\
\hline VII & -2.25 & -1.66 & 70.09 & 70.71 & 209.39 & 63.58 & 64.01 & 208.5933 \\
\hline VIII & -2.42 & -1.68 & 108.25 & 105.54 & 206.26 & 81.12 & 79.69 & 207.3042 \\
\hline IX & -2.50 & -1.05 & 182.28 & 178.41 & 202.27 & 123.60 & 122.20 & 204.4556 \\
\hline $\mathrm{X}$ & -2.63 & +0.1 & 0.00 & 0.00 & 210.45 & 0.00 & 0.00 & 209.5884 \\
\hline
\end{tabular}


data show inverse results. The isomer $\mathrm{X}$, which is an anti-aromatic molecule, is the most stable isomer and the aromatic isomers I and II are unstable. Table 1 shows that as the number of keto groups increases the stability increases and the aromaticity decreases. These calculations show that we cannot determine the relative stability of isomers of a molecule based only on aromaticity of the isomers. In the cyanuric acid studies, ${ }^{2-9,12}$ usually only the isomers I and X are considered, while the results of this work suggest that the isomers III, VII and VIII are more stable than isomer I and should be taken into account. The stability trends of the isomers are similar in the aqueous and gas phases.

Figure 2 shows the optimized transition state (TS) structures for isomerizations in cyanuric acid. The geometric parameters of these TS structures have been collected

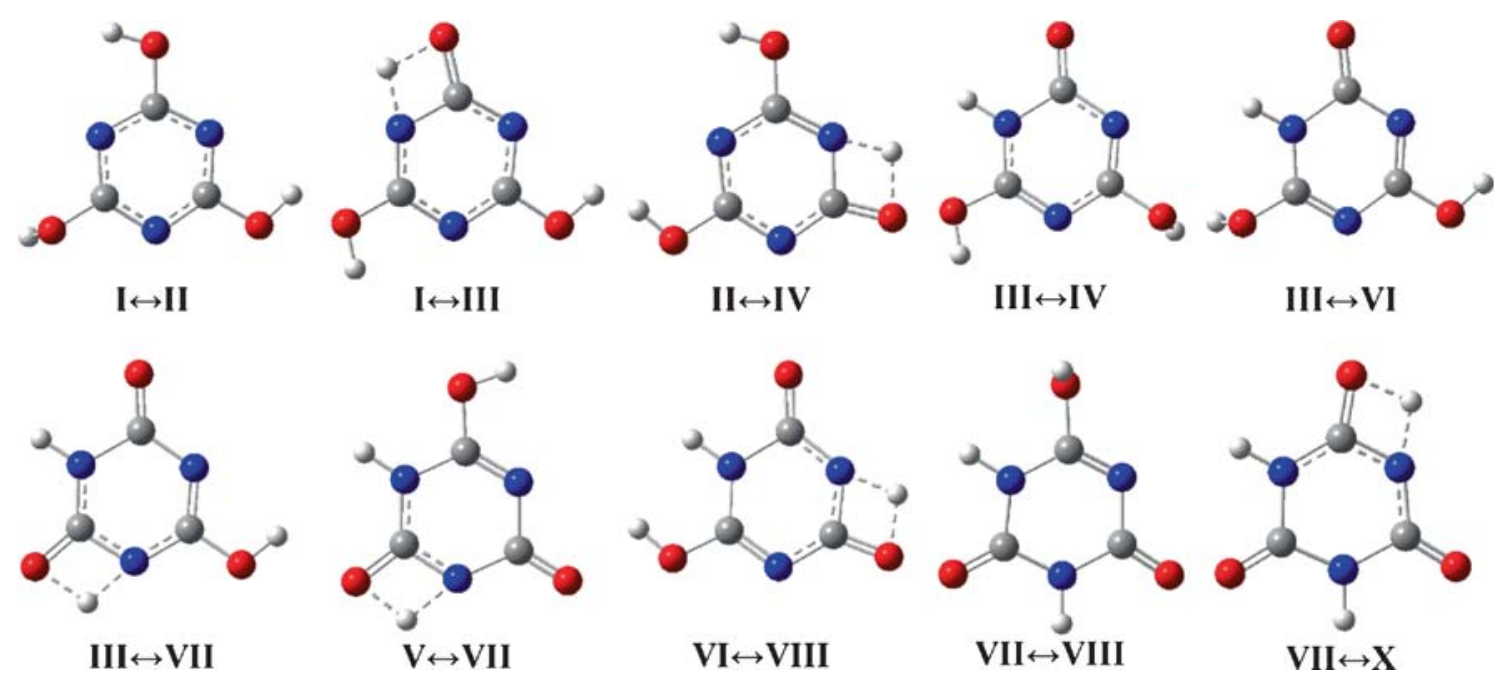

Figure 2. The optimized TS structures of the intramolecular proton transfers and internal O-H rotations in cyanuric acid.

Table 2. The calculated activation energies $\left(E_{a}\right)$, activation free energies $\left(\Delta G^{\#}\right)$ and the imaginary frequencies $(\nu)$ of the TS structures of the isomerizations in cyanuric acid.

\begin{tabular}{|c|c|c|c|c|c|c|}
\hline \multirow[b]{2}{*}{ Isomerization } & \multicolumn{3}{|c|}{ Gas Phase } & \multicolumn{3}{|c|}{ Aqueous phase } \\
\hline & $\mathrm{E}_{\mathrm{a}}(\mathrm{kJ} / \mathrm{mol})$ & $\Delta \mathrm{G}^{\#}(\mathrm{~kJ} / \mathrm{mol})$ & $v\left(\mathrm{~cm}^{-1}\right)$ & $\mathrm{E}_{\mathrm{a}}(\mathrm{kJ} / \mathrm{mol})$ & $\Delta \mathrm{G}^{\#}(\mathrm{~kJ} / \mathrm{mol})$ & $v\left(\mathrm{~cm}^{-1}\right)$ \\
\hline $\mathrm{I} \rightarrow \mathrm{II}$ & 40.62 & 41.14 & -581.44 & 33.76 & 34.65 & -533.97 \\
\hline $\mathrm{II} \rightarrow \mathrm{I}$ & 36.35 & 36.98 & -581.44 & 33.25 & 34.10 & -533.97 \\
\hline $\mathrm{I} \rightarrow \mathrm{III}$ & $\begin{array}{l}145.15 \\
144.3^{\mathrm{a}}\end{array}$ & 145.19 & -1870.03 & 145.90 & 146.22 & -1927.15 \\
\hline $\mathrm{III} \rightarrow \mathrm{I}$ & 151.74 & 153.13 & -1870.03 & 166.67 & 167.75 & -1927.15 \\
\hline $\mathrm{II} \rightarrow \mathrm{IV}$ & 147.12 & 147.02 & -1867.89 & 146.22 & 146.56 & -1925.24 \\
\hline $\mathrm{IV} \rightarrow \mathrm{II}$ & 148.19 & 149.71 & -1867.89 & 165.22 & 166.44 & -1925.24 \\
\hline $\mathrm{III} \rightarrow \mathrm{IV}$ & 45.29 & 45.65 & -595.98 & 36.67 & 37.33 & -555.56 \\
\hline $\mathrm{IV} \rightarrow \mathrm{III}$ & 35.48 & 36.25 & -595.98 & 34.38 & 35.13 & -555.56 \\
\hline $\mathrm{III} \rightarrow \mathrm{VI}$ & 42.55 & 43.24 & -463.99 & 32.35 & 33.36 & -477.72 \\
\hline $\mathrm{VI} \rightarrow \mathrm{III}$ & 10.24 & 12.41 & -463.99 & 17.61 & 19.53 & -477.72 \\
\hline $\mathrm{III} \rightarrow \mathrm{VII}$ & $\begin{array}{l}133.58 \\
132.4^{\mathrm{a}}\end{array}$ & 133.74 & -1880.16 & 141.75 & 142.06 & -1934.78 \\
\hline $\mathrm{VII} \rightarrow \mathrm{III}$ & 179.45 & 180.90 & -1880.16 & 188.65 & 189.87 & -1934.78 \\
\hline $\mathrm{V} \rightarrow \mathrm{VII}$ & 123.11 & 124.71 & -1908.91 & 132.61 & 133.59 & -1947.28 \\
\hline $\mathrm{VII} \rightarrow \mathrm{V}$ & 210.19 & 211.12 & -1908.91 & 206.78 & 207.82 & -1947.28 \\
\hline $\mathrm{VI} \rightarrow \mathrm{VIII}$ & 129.28 & 129.24 & -1897.45 & 133.40 & 134.27 & -1941.09 \\
\hline $\mathrm{VIII} \rightarrow \mathrm{VI}$ & 169.30 & 172.39 & -1897.45 & 177.51 & 180.21 & -1941.09 \\
\hline $\mathrm{VII} \rightarrow \mathrm{VIII}$ & 44.78 & 45.47 & -444.56 & 33.03 & 33.88 & -478.04 \\
\hline $\mathrm{VIII} \rightarrow \mathrm{VII}$ & 6.61 & 10.64 & -444.56 & 15.50 & 18.19 & -478.04 \\
\hline $\mathrm{VII} \rightarrow \mathrm{X}$ & $\begin{array}{l}125.43 \\
124.3^{\mathrm{a}}\end{array}$ & 126.14 & -1905.31 & 133.90 & 134.64 & -1948.34 \\
\hline $\mathrm{X} \rightarrow \mathrm{VII}$ & 195.53 & 196.85 & -1905.31 & 197.48 & 198.64 & -1948.34 \\
\hline
\end{tabular}

${ }^{a}$ from ref ${ }^{1}$. 
as Figure S2 in Supplementary Information. The isomerizations I $\leftrightarrow \mathrm{II}, \mathrm{III} \leftrightarrow \mathrm{IV}, \mathrm{III} \leftrightarrow \mathrm{VI}$ and $\mathrm{VII} \leftrightarrow \mathrm{VIII}$ are due to internal $\mathrm{O}-\mathrm{H}$ rotations in which the $\mathrm{H}$ atom rotates $180^{\circ}$ around its $\mathrm{C}-\mathrm{O}$ axis. The isomerizations $\mathrm{I} \leftrightarrow \mathrm{III}, \mathrm{II} \leftrightarrow \mathrm{IV}, \mathrm{III} \leftrightarrow \mathrm{VII}, \mathrm{V} \leftrightarrow \mathrm{VII}, \mathrm{VI} \leftrightarrow \mathrm{VIII}$ and $\mathrm{VII} \leftrightarrow \mathrm{X}$ are due to intramolecular proton transfers or keto-enol tautomerism in which a hydrogen atom is transferred between an oxygen atom and a nitrogen atom.

The energy barriers for the forward and backward paths of isomerizations, shown in Figure 2, were calculated.
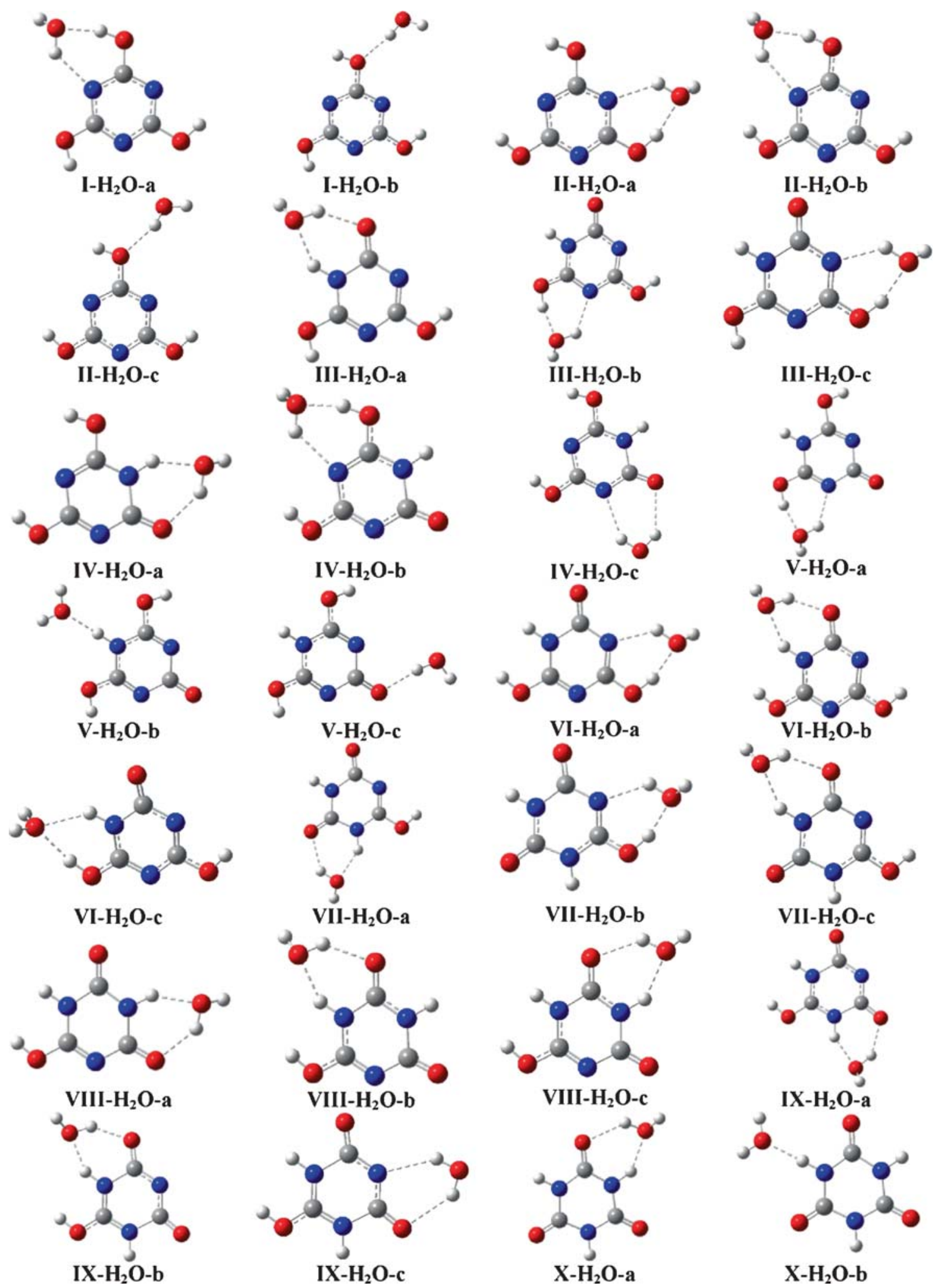

$\mathrm{X}-\mathrm{H}_{2} \mathrm{O}-\mathrm{b}$

Figure 3. The optimized structures of the mono-hydrated isomers of cyanuric acid. 
The calculated activation energies $\left(\mathrm{E}_{\mathrm{a}}\right)$, activation free energies $\left(\Delta G^{\#}\right)$ and the imaginary frequencies of the TS structures $(v)$ of the isomerizations have been summarized in Table 2. The energy barriers of the internal O-H rotations are smaller than $45 \mathrm{~kJ} / \mathrm{mol}$ and the $v$ values of their TS structures are about -450 to $-600 \mathrm{~cm}^{-1}$. The rotations $\mathrm{VI} \rightarrow \mathrm{III}$ and $\mathrm{VIII} \rightarrow \mathrm{VII}$ have the smallest activation energies; because of the instability of the isomers VI and VIII due to $\mathrm{H}-\mathrm{H}$ repulsion in their structures (Figure 1). The intramolecular proton transfers have

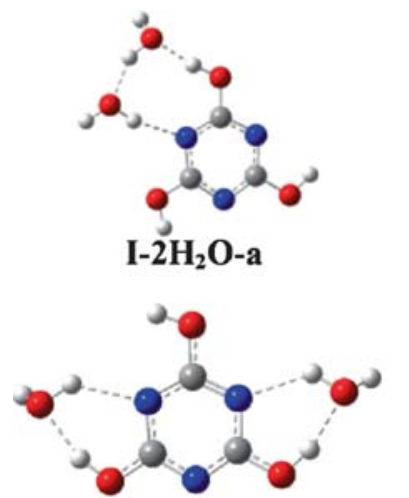

II-2 $\mathrm{H}_{2} \mathrm{O}-\mathrm{c}$

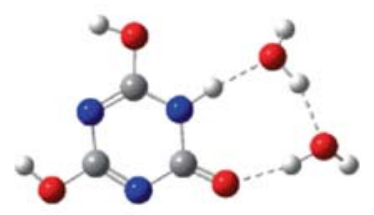

IV-2 $\mathrm{H}_{2} \mathrm{O}$-a

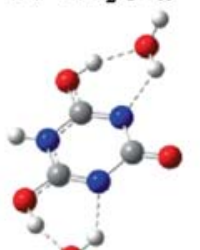

$\mathrm{V}-2 \mathrm{H}_{2} \mathrm{O}-\mathrm{b}$

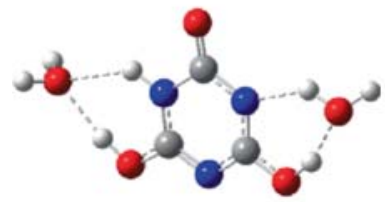

VI-2 $\mathrm{H}_{2} \mathrm{O}-\mathrm{c}$

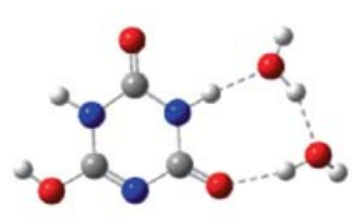

VIII-2 $\mathrm{H}_{2} \mathrm{O}$-a

32

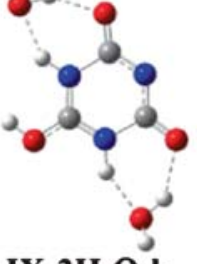

IX-2 $\mathrm{H}_{2} \mathrm{O}-\mathrm{b}$
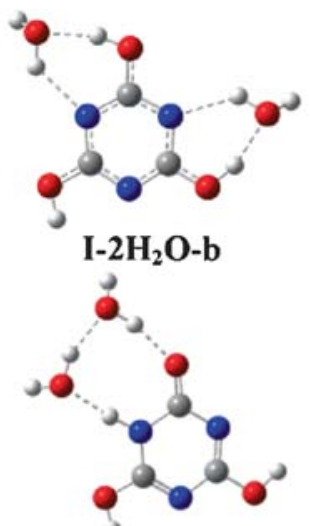

III-2 $\mathrm{H}_{2} \mathrm{O}-\mathrm{a}$
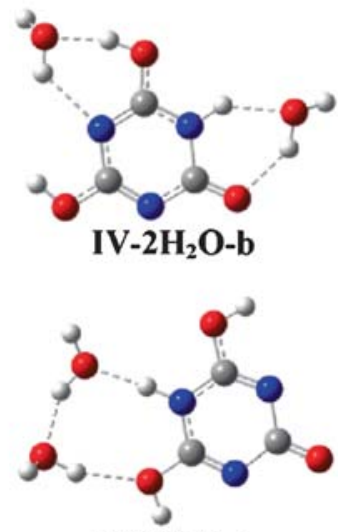

V-2 $\mathrm{H}_{2} \mathrm{O}-\mathrm{c}$
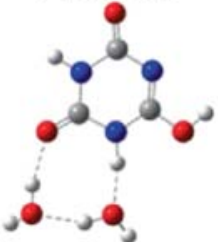

VII-2 $\mathrm{H}_{2} \mathrm{O}$-a
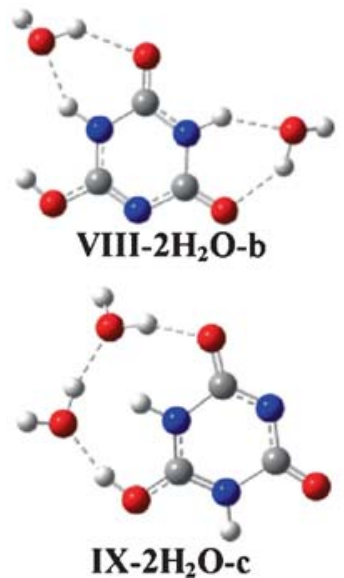

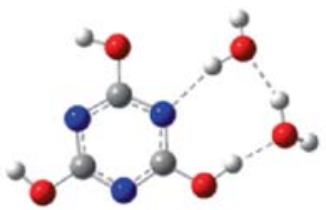

II-2 $\mathrm{H}_{2} \mathrm{O}-\mathrm{a}$

3.

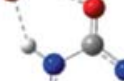

000

os

III-2 $\mathrm{H}_{2} \mathrm{O}-\mathrm{b}$

D. - 0

$10^{\circ}$

200

30

IV-2 $\mathrm{H}_{2} \mathrm{O}$-c

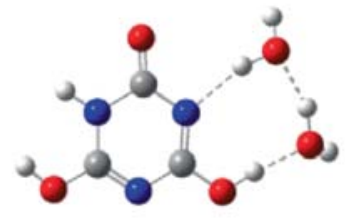

VI-2 $\mathrm{H}_{2} \mathrm{O}$-a

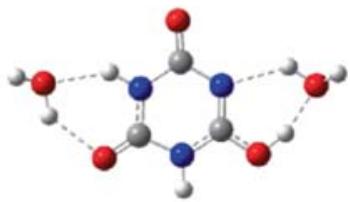

VII-2 $\mathrm{H}_{2} \mathrm{O}-\mathrm{b}$

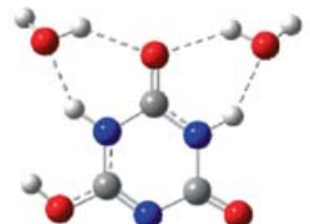

VIII-2 $\mathrm{H}_{2} \mathrm{O}-\mathrm{c}$

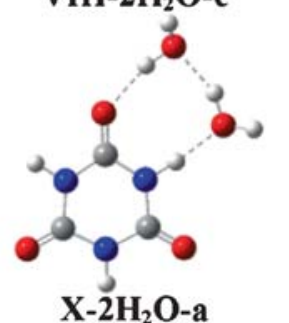

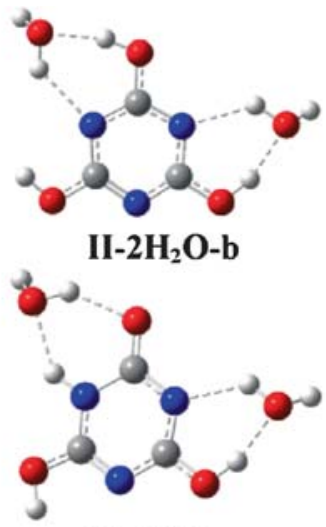

III-2 $\mathrm{H}_{2} \mathrm{O}-\mathrm{c}$

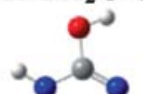

-

o. o

$\mathrm{V}-2 \mathrm{H}_{2} \mathrm{O}-\mathrm{a}$

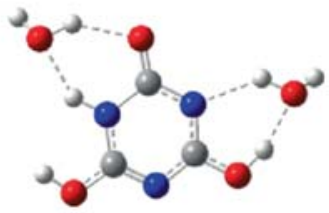

VI-2 $\mathrm{H}_{2} \mathrm{O}-\mathrm{b}$

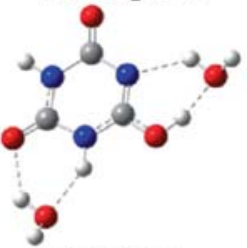

VII-2 $\mathrm{H}_{2} \mathrm{O}-\mathrm{c}$

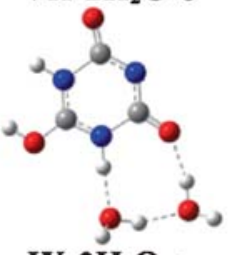

IX-2 $\mathrm{H}_{2} \mathrm{O}-\mathrm{a}$

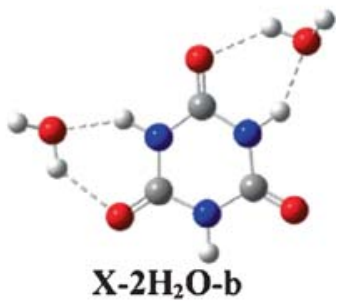

Figure 4. The optimized structures of the di-hydrated isomers of cyanuric acid. 
higher energy barriers (130-210 kJ/mol) and the $v$ values of their TS structures are about $-1900 \mathrm{~cm}^{-1}$ which correspond with stretching vibrations. Because of the stability of the keto isomers, generally, the activation energies of the enol $\rightarrow$ keto tautomerisms are smaller than those for keto $\rightarrow$ enol tautomerisms. The $\Delta \mathrm{G}^{\#}$ values are about few $\mathrm{kJ} / \mathrm{mol}$ larger than the $\mathrm{E}_{\mathrm{a}}$ values which indicates that the entropies of the TS structures are smaller than those for the corresponding isomers.

Although the $\mathrm{O}-\mathrm{H}$ rotations can occur at ambient condition, the activation energies of the intramolecular proton transfers are too high to take place easily. There are many studies on the water-assisted proton transfers in the hydrated molecules. These studies show that the energy barriers of the intramolecular proton transfers decrease as these reactions are catalyzed by water molecules. ${ }^{14,15,22,23}$

The cyanuric acid isomers can be hydrated from different sites. Therefore, we considered different paths for hydration of each isomer (a, b and c). Figures 3 and 4 show the optimized structures of the mono- and di-hydrated isomers of cyanuric acid in gas phase, respectively. The geometric parameters of the hydrated structures have been collected as Figure S1 in Supplementary Information.

In the mono-hydrated isomers, each water molecule forms two hydrogen bonds with two different sites of cyanuric acid; therefore, the water molecule and the isomer produce a hexagonal ring through the hydrogen bonds. In the di-hydrated structure a, two water molecules and a cyanuric molecule form an octahedral ring.

The relative enthalpies $(\Delta \mathrm{H})$ and Gibbs free energies $(\Delta \mathrm{G})$ of the non-hydrated, mono- and di-hydrated isomers of cyanuric acid are compared in Table 3 . The relative energies range from 0.0 to $180 \mathrm{~kJ} / \mathrm{mol}$, for the non-hydrated isomers in gas phase. The mono- and di-hydration decrease this range so that the energy ranges become $0.0-170$ and $0.0-165 \mathrm{~kJ} / \mathrm{mol}$, respectively. Also, the isomer VIII is more stable than the isomer III in gas phase while their di-hydrated forms have the same stability. Generally, the hydrations do not change the stability trend among the CA isomers and the isomer $\mathrm{X}$ is the most stable isomer in the non-, mono- and d-hydrated forms.

Figure 5 shows the optimized TS structures of the water-assisted intramolecular proton transfers in cyanuric

Table 3. Comparison of the relative energies of the non-hydrated, mono-hydrated and di-hydrated isomers of cyanuric acid in gas phase. The letters a, b and c are related to hydrations from different sites (Figures 3 and 4).

\begin{tabular}{|c|c|c|c|c|c|c|}
\hline \multirow[b]{2}{*}{ Isomer } & \multicolumn{2}{|c|}{ non-hydrated } & \multicolumn{2}{|c|}{ mono-hydrated } & \multicolumn{2}{|c|}{ di-hydrated } \\
\hline & $\Delta \mathrm{H}(\mathrm{kJ} / \mathrm{mol})$ & $\Delta \mathrm{G}(\mathrm{kJ} / \mathrm{mol})$ & $\Delta \mathrm{H}(\mathrm{kJ} / \mathrm{mol})$ & $\Delta \mathrm{G}(\mathrm{kJ} / \mathrm{mol})$ & $\Delta \mathrm{H}(\mathrm{kJ} / \mathrm{mol})$ & $\Delta \mathrm{G}(\mathrm{kJ} / \mathrm{mol})$ \\
\hline \multirow[t]{2}{*}{ I } & 122.56 & 125.81 & 114.01 (a) & 119.74 (a) & $114.43(\mathrm{a})$ & 120.87 (a) \\
\hline & & & 145.51 (b) & $136.63(\mathrm{~b})$ & 113.31 (b) & $121.50(\mathrm{~b})$ \\
\hline \multirow[t]{3}{*}{ II } & 126.84 & 129.96 & $119.33(\mathrm{a})$ & $124.83(\mathrm{a})$ & 120.31 (a) & $126.33(\mathrm{a})$ \\
\hline & & & $126.62(\mathrm{~b})$ & $131.45(\mathrm{~b})$ & $127.01(\mathrm{~b})$ & 133.99 (b) \\
\hline & & & $149.67(\mathrm{c})$ & $141.10(\mathrm{c})$ & 129.49 (c) & $136.25(\mathrm{c})$ \\
\hline \multirow[t]{3}{*}{ III } & 115.96 & 117.87 & 108.57 (a) & 111.98 (a) & 106.38 (a) & 109.10 (a) \\
\hline & & & 99.59 (b) & $104.48(b)$ & $102.45(b)$ & $108.75(b)$ \\
\hline & & & $103.23(\mathrm{c})$ & $108.17(\mathrm{c})$ & $105.10(\mathrm{c})$ & $111.36(\mathrm{c})$ \\
\hline \multirow[t]{3}{*}{ IV } & 125.77 & 127.27 & 117.52 (a) & 120.61 (a) & 115.14 (a) & 118.01 (a) \\
\hline & & & $117.93(b)$ & $121.34(b)$ & $119.94(b)$ & 124.79 (b) \\
\hline & & & $137.53(\mathrm{c})$ & $131.06(\mathrm{c})$ & 137.37 (c) & 131.99 (c) \\
\hline \multirow[t]{3}{*}{ V } & 157.17 & 157.12 & 136.69 (a) & 140.44 (a) & 127.10 (a) & 132.35 (a) \\
\hline & & & $157.91(b)$ & $156.77(b)$ & $125.29(\mathrm{~b})$ & $132.51(\mathrm{~b})$ \\
\hline & & & $167.09(\mathrm{c})$ & $159.60(\mathrm{c})$ & $168.38(\mathrm{c})$ & $165.96(\mathrm{c})$ \\
\hline \multirow[t]{3}{*}{ VI } & 148.27 & 148.69 & 136.61 (a) & 139.94 (a) & 133.91 (a) & 137.88 (a) \\
\hline & & & $133.87(b)$ & $136.66(b)$ & 131.42 (b) & $136.77(\mathrm{~b})$ \\
\hline & & & $132.57(\mathrm{c})$ & $132.34(\mathrm{c})$ & $129.82(\mathrm{c})$ & $132.34(\mathrm{c})$ \\
\hline \multirow[t]{3}{*}{ VII } & 70.09 & 70.71 & $65.81(\mathrm{a})$ & 67.17 (a) & 63.89 (a) & $64.88(a)$ \\
\hline & & & 50.92 (b) & $54.92(b)$ & $62.83(\mathrm{~b})$ & $66.41(\mathrm{~b})$ \\
\hline & & & $69.06(\mathrm{c})$ & $70.53(\mathrm{c})$ & $56.81(\mathrm{c})$ & $61.34(\mathrm{c})$ \\
\hline \multirow[t]{3}{*}{ VIII } & 108.25 & 105.54 & $106.36(\mathrm{a})$ & 105.05 (a) & $106.34(\mathrm{a})$ & $105.01(\mathrm{a})$ \\
\hline & & & 97.07 (b) & 96.83 (b) & $103.33(b)$ & 104.42 (b) \\
\hline & & & $112.14(\mathrm{c})$ & $108.72(\mathrm{c})$ & $111.18(\mathrm{c})$ & $110.58(\mathrm{c})$ \\
\hline \multirow[t]{3}{*}{ IX } & 182.28 & 178.41 & $169.65(\mathrm{a})$ & $169.01(\mathrm{a})$ & $166.42(\mathrm{a})$ & 166.24 (a) \\
\hline & & & $162.41(\mathrm{~b})$ & $162.74(\mathrm{~b})$ & $159.23(\mathrm{~b})$ & $162.12(\mathrm{~b})$ \\
\hline & & & $193.07(\mathrm{c})$ & $179.42(\mathrm{c})$ & $135.34(\mathrm{c})$ & $138.25(\mathrm{c})$ \\
\hline \multirow[t]{2}{*}{$X$} & 0.00 & 0.00 & 0.00 (a) & 0.00 (a) & 0.00 (a) & 0.00 (a) \\
\hline & & & 2.27 (b) & 1.84 (b) & 8.64 (a) & 8.93 (b) \\
\hline
\end{tabular}


acid. The geometric parameters of these TS structures have been collected as Figure S2 in Supplementary Information. The proton is transferred through the rings formed from the water molecules and a cyanuric acid isomer. In other words, water molecule gets a proton from donor site of cyanuric acid and gives another proton to its acceptor site. Two and three synchronous proton transfers occur in the mono- and di-hydrated TS structures, respectively.
The energy barriers of the water-assisted tautomerisms in cyanuric acid were calculated from the energy differences between the hydrated isomers (Figures 3 and 4) and their corresponding TS structures (Figure 5). Since each TS structure connects two different hydrated isomers, two energy barriers (for the forward and backward proton transfers) were calculated for each TS. The activation energies $\left(E_{a}\right)$ and free energies $\left(\Delta G^{\#}\right)$ of the tautomerisms in the non-hydrated, mono- and
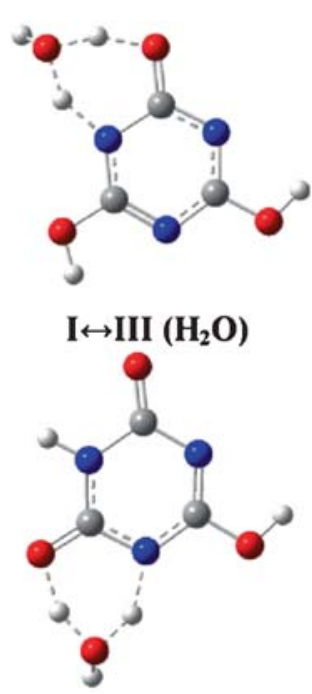

III $\leftrightarrow$ VII $\left(\mathrm{H}_{2} \mathbf{O}\right)$

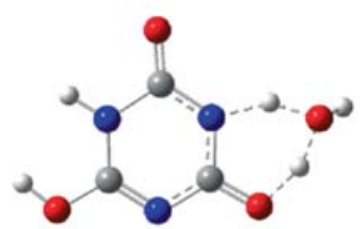

$\mathrm{VI \leftrightarrow VIII}\left(\mathrm{H}_{2} \mathbf{O}\right)$
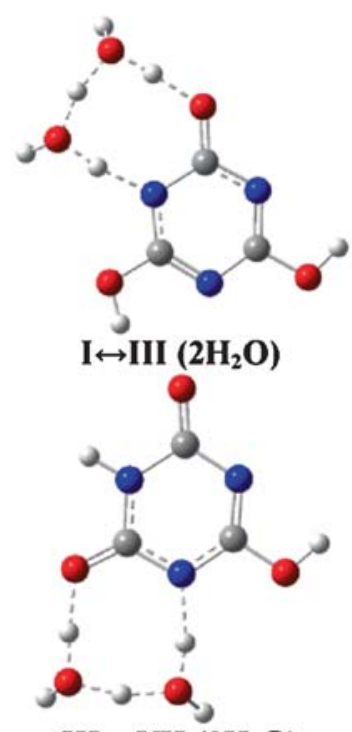

III $\leftrightarrow$ VII $\left(2 \mathrm{H}_{2} \mathrm{O}\right)$

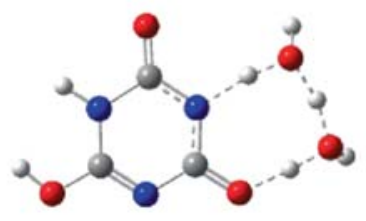

$\mathrm{VI \leftrightarrow}$ VIII $\left(2 \mathrm{H}_{2} \mathrm{O}\right)$
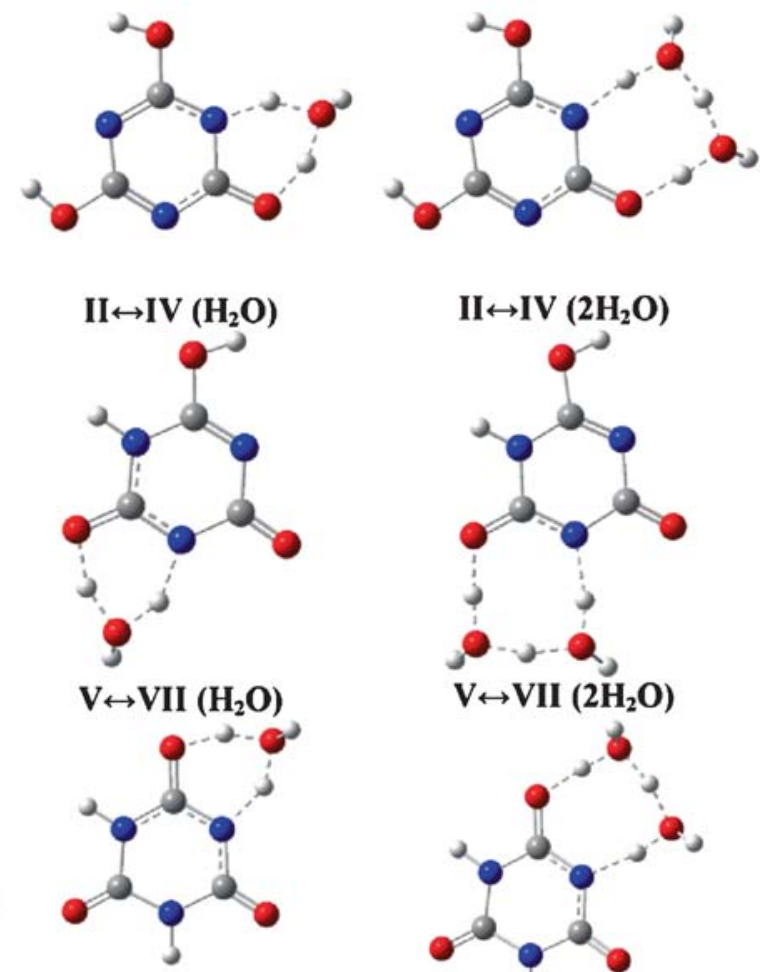

$\mathrm{VII} \leftrightarrow \mathrm{X}\left(\mathrm{H}_{2} \mathrm{O}\right)$

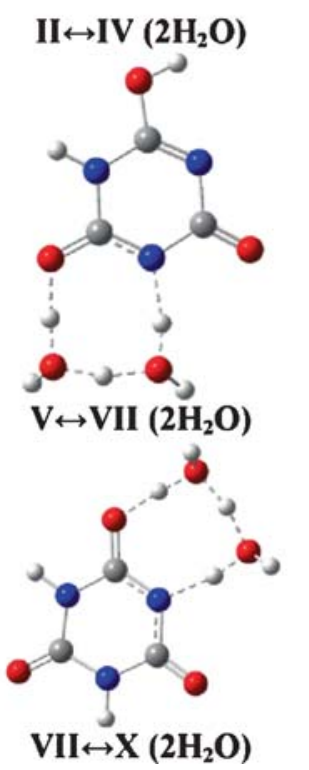

Figure 5. The optimized TS structures of the water-assisted intramolecular proton transfers in cyanuric acid.

Table 4. Comparison of the energy barriers of the intramolecular proton transfers in the non-hydrated and mono- and di-hydrated isomers of cyanuric acid.

\begin{tabular}{|c|c|c|c|c|c|c|}
\hline \multirow[b]{2}{*}{ Isomer } & \multicolumn{2}{|c|}{ non-hydrated } & \multicolumn{2}{|c|}{ mon-hydrated } & \multicolumn{2}{|c|}{ di-hydrated } \\
\hline & $\mathrm{E}_{\mathrm{a}}(\mathrm{kJ} / \mathrm{mol})$ & $\Delta \mathrm{G}^{\#}(\mathrm{~kJ} / \mathrm{mol})$ & $\mathrm{E}_{\mathrm{a}}(\mathrm{kJ} / \mathrm{mol})$ & $\Delta \mathrm{G}^{\#}(\mathrm{~kJ} / \mathrm{mol})$ & $\overline{\mathrm{E}_{\mathrm{a}}(\mathrm{kJ} / \mathrm{mol})}$ & $\Delta \mathrm{G}^{\#}(\mathrm{~kJ} / \mathrm{mol})$ \\
\hline $\mathrm{I} \rightarrow \mathrm{III}$ & 145.15 & 145.19 & 39.91 & 47.57 & 33.13 & 44.07 \\
\hline $\mathrm{III} \rightarrow \mathrm{I}$ & 151.74 & 153.13 & 45.35 & 55.34 & 41.18 & 55.84 \\
\hline $\mathrm{II} \rightarrow \mathrm{IV}$ & 147.12 & 147.02 & 41.67 & 49.31 & 34.82 & 45.88 \\
\hline $\mathrm{IV} \rightarrow \mathrm{II}$ & 148.19 & 149.71 & 43.48 & 53.54 & 39.99 & 54.21 \\
\hline $\mathrm{III} \rightarrow \mathrm{VII}$ & 133.58 & 133.74 & 26.28 & 33.66 & 17.39 & 27.35 \\
\hline $\mathrm{VII} \rightarrow \mathrm{III}$ & 179.45 & 180.90 & 60.06 & 70.94 & 48.64 & 63.91 \\
\hline $\mathrm{V} \rightarrow \mathrm{VII}$ & 123.11 & 124.71 & 17.99 & 25.47 & 11.74 & 22.39 \\
\hline $\mathrm{VII} \rightarrow \mathrm{V}$ & 210.19 & 211.12 & 81.18 & 92.12 & 64.34 & 79.58 \\
\hline $\mathrm{VI} \rightarrow \mathrm{VIII}$ & 129.28 & 129.24 & 29.57 & 36.55 & 25.44 & 35.71 \\
\hline $\mathrm{VIII} \rightarrow \mathrm{VI}$ & 169.30 & 172.39 & 59.83 & 71.44 & 53.01 & 68.58 \\
\hline $\mathrm{VII} \rightarrow \mathrm{X}$ & 125.43 & 126.14 & 20.59 & 27.90 & 13.37 & 23.68 \\
\hline $\mathrm{X} \rightarrow \mathrm{VII}$ & 195.53 & 196.85 & 71.52 & 82.77 & 56.81 & 72.40 \\
\hline
\end{tabular}


di-hydrated isomers of cyanuric acid have been compared in Table 4. The energy barriers decrease about $100-130 \mathrm{~kJ} / \mathrm{mol}$ when the proton transfers are catalyzed by one water molecule. The catalytic effect of two water molecules is slightly more so that the energy barriers of tautomerisms in the di-hydrated isomers are about $110-145 \mathrm{~kJ} / \mathrm{mol}$ lower than those in the absence of the water molecules. In the non-hydrated isomers, the proton transfer occurs through a tetragonal ring which leads in an unstable TS structure which consequently increases in the activation energy. In the hydrated structures, the proton transfers take place through larger rings, and therefore, stable TS structures are formed.

\section{Conclusions}

Although the enolic isomers of cyanuric acid are aromatic, they are more unstable than the keto isomers. Usually, in the cyanuric studies, only two isomers are considered: one with three enolic groups and another isomer with three keto groups. This work showed that the isomers with one and two keto groups are more stable than the aromatic isomer with three enolic groups.

Micro-hydration of the cyanuric acid isomers does not change their relative stabilities so that the isomer with three keto groups is the most stable isomer in the aqueous and gas phases and in the mono- and di-hydrated forms.

The energy barriers of the internal $\mathrm{O}-\mathrm{H}$ rotation in cyanuric acid are smaller than $45 \mathrm{~kJ} / \mathrm{mol}$, therefore, the rotations of $\mathrm{H}$ atoms about its $\mathrm{C}-\mathrm{O}$ axis can easily take place. On the other hand, the activation energies of intramolecular proton transfers (tautomerisms) in cyanuric acids are $130-210 \mathrm{~kJ} / \mathrm{mol}$. The micro-hydration decreases the energy barriers of the proton transfers so that the activation energies of the tautomerisms are about $40-80 \mathrm{~kJ} / \mathrm{mol}$ and $30-60 \mathrm{~kJ} / \mathrm{mol}$ in the mono- and di-hydrated isomers, respectively.

\section{Supplementary Information (SI)}

All additional information pertaining to geometrical parameters of the hydrated and non-hydrated isomers and the TS structures are given in the supplementary information (Figures S1 and S2). The supplementary information is available at www.ias.ac.in/chemsci.

\section{Acknowledgments}

The author wishes to express his thanks to the Science and Research Branch of Islamic Azad University in Tehran.

\section{References}

1. Liang X, Zheng W, Wong N B, Li J and Tian A $2004 \mathrm{~J}$. Mol. Struct. (THEOCHEM) 672151

2. Zabardasti A 2007 Chem. Heterocycl. Compd. 431344

3. Zabardasti A, Kakanejadi A, Ghenaatian F and Bigleri Z 2010 Mol. Simul. 36960

4. Seto C T and Whitesides G M $1990 \mathrm{~J}$. Am. Chem. Soc. 1126409

5. Ranganathan A, Pedireddi V R and Rao C N R $1999 \mathrm{~J}$. Am. Chem. Soc. 1211752

6. Damodaran K, Sanjayan G J, Rajamohanan P R, Ganapathy S and Ganesh K N 2001 Org. Lett. 31921

7. Pedireddi V R and Belhekar D 2002 Tetrahedron 58 2937

8. Kannappan K, Werblowsky T L, Rim K T, Berne B J and Flynn G W 2007 J. Phys. Chem. B 1116634

9. Zhang H M, Pei Z K, Xie Z X, Long L S, Mao B W, Xu X and Zheng L S 2009 J. Phys. Chem. C 11313940

10. Klotz I M and Askounis T 1947 J. Am. Chem. Soc. 69 801

11. Newman R and Badger R M 1952 J. Am. Chem. Soc. 74 3545

12. Prabhaharan M, Prabakaran A R, Srinivasan S and Gunasekaran S 2015 Spectrochim. Acta A 138711

13. Paine S W and Salam A 2013 Int. J. Quant. Chem. 113 1245

14. Valadbeigi Y and Farrokhpour H 2014 Struct. Chem. 25 1395

15. Valadbeigi $\mathrm{Y}$ and Farrokhpour H 2014 RSC Adv. 4 61643

16. Kroke E, Schwarz M, Horath-Bordon E, Kroll P, Noll B and Norman A D 2002 New. J. Chem. 26508

17. Fukui K 1981 Acc. Chem. Res. 14363

18. Tomasi J, Mennucci B and Cammi R 2005 Chem. Rev. 1052999

19. Stanger A 2006 J. Org. Chem. 71883

20. Fallah-Bagher-Shaidaei H, Wannere C S, Corminboeuf C, Puchta R and Schleyer P V R 2006 Org. Lett. 8863

21. Frisch M J, Trucks G W, Schlegel H B, Scuseria G E, Robb M A, Cheeseman J R, Scalmani G, Barone V, Mennucci B, Petersson G A, Nakatsuji H, Caricato M, Li X, Hratchian H P, Izmaylov A F, Bloino J, Zheng G, Sonnenberg J L, Hada M, Ehara M, Toyota K, Fukuda R, Hasegawa J, Ishida M, Nakajima T, Honda Y, Kitao O, Nakai H, Vreven T, Montgomery J A, Jr., Peralta J E, Ogliaro F, Bearpark M, Heyd J J, Brothers E, Kudin K N, Staroverov V N, Kobayashi R, Normand J, Raghavachari K, Rendell A, Burant J C, Iyengar S S, Tomasi J, Cossi M, Rega N, Millam J M, Klene M, Knox J E, Cross J B, Bakken V, Adamo C, Jaramillo J, Gomperts R, Stratmann R E, Yazyev O, Austin A J, Cammi R, Pomelli C, Ochterski J W, Martin R L, Morokuma K, Zakrzewski V G, Voth G A, Salvador P, Dannenberg J J, Dapprich S, Daniels A D, Farkas O, Foresman J B, Ortiz J V, Cioslowski J and Fox D J 2009 Gaussian 09, Revision A.1. (Gaussian, Inc.: Wallingford)

22. Markova N, Enchev V and Timtcheva I 2005 J. Phys. Chem. A 1091981

23. Li D and Ai H 2009 J. Phys. Chem. B 11311732 